\title{
O uso da web em produção multimídia na área de artes visuais
}

Andréia Machado Oliveira Tania Mara Galli Fonseca Maria Cristina Villanova Biazus

\section{Using the webin multimedia production in the field of fine arts}


Resumo: O presente trabalho aborda o uso da web em uma proposta pedagógica colaborativa a partir de uma produção multimídia na área de artes visuais. Tal proposta constitui-se da produção de videoclips, realizados por alunos da $6^{\underline{a}}$ série do ensino fundamental de um colégio da rede privada. Buscou-se investigar como produzir construções imagéticas digitais nas interpretações associativas entre as diversas linguagens: visual, verbal e sonora. Nas imagens digitais habitam uma usina de signos que devem ser navegados e (re)significados. Os videoclips se apresentam como produção coletiva que se constitui como um efeito de contingências de um processo criativo e emerge como uma obra original e singular, já que é criada a partir dos jogos pertinentes aos agenciamentos entre os sujeitos/máquina e obra, compostos por elementos singulares em um recorte de espaço/tempo histórico. Afirma-se, aqui, a importância de práticas pedagógicas que se fundamentam sobre metodologias multimídia a partir de processos abertos e colaborativos.

Palavras-chave: Multimídia, web, colaboração, arte.

Abstract: This work discusses the use of the web in a cooperative educational proposal from a multimedia production in the field of Fine Arts. Such proposal is a videoclip produced by six graders from a private school. The videoclips were developed during six months in the School Computing Lab by pairs of students who have initially chosen the songs and prepare the screenplay. Then, the clip images were selected from the web and the school image database, and worked in an image editing software in order to re-signify and appropriate them. The goal was investigating the way of producing imagetic pieces in the associating interpretations among several languages: visual, verbal and sound. Within the digital images there is a source of signs which shall be navigated and re-signified. The importance of educational practices based upon the multimedia methodologies from open and cooperative processes is herein assessed.

Keywords: Multimedia, web, cooperation, art.

OLIVEIRA, Andréia Machado; FONSECA, Tania Mara Galli ; BIAZUS, Maria Cristina Villanova . O uso da web em produção multimídia na área de artes visuais. Informática na Educação: teoria \& prática, Porto Alegre, v.10, n.1, p.41-55, jan./jun. 2007. 


\section{Introdução}

O presente trabalho aborda o uso da web em uma proposta pedagógica colaborativa a partir de uma produção multimídia na área de artes visuais. Tal proposta constitui-se da produção de videoclips por alunos do ensino fundamental da $6^{\text {a }}$ - tarde, na disciplina de Educação Artística, em uma instituição de ensino fundamental e médio da rede privada da cidade de Porto Alegre. O Colégio apresenta, nos laboratórios de informática, infra-estrutura adequada para desenvolver propostas que utilizam a web e programas de edição de imagem. Os alunos constroem videoclips, em duplas, selecionando imagens da web e do banco de imagens da escola, que, posteriormente, são trabalhadas em programas de edição de imagens com a finalidade de (re)significação e apropriação.

Observou-se que o uso da web promoveu processos de criação, indo além das imagens clichês. O acesso à web neste trabalho é aberto, permitindo que os alunos naveguem de acordo com as necessidades do próprio trabalho, tendo atitudes exploratórias e colaborativas entre as duplas. O trabalho teve duração de seis meses: primeiro mês em sala de aula e os demais meses no laboratório de informática do Colégio. Buscou-se investigar a relação aluno-informática dentro de um ambiente colaborativo, bem como o uso da web nas construções imagéticas, problematizando conceitos como (re)significação, informação e criação. Após, concluída a produção dos videoclips, os alunos apresentaram os trabalhos à comunidade escolar na Mostra de Informática do Colégio.

\section{Motivação do projeto}

Otrabalho do videoclip vem sendo desenvolvido desde 2000, na disciplina de Educação Artística, com as turmas de $6^{a}$ série do turno da tarde. Os videoclips sofrem alterações e inova- ções de acordo com os projetos desenvolvidos na série em cada ano, participando de projetos interdisciplinares, como: "Cabeças bem feitas", "Que país é este?", "Conscientizar para mudar" e outros. Percebe-se que este trabalho oportuniza aos alunos explorarem alguns conceitos pertinentes à contemporaneidade, como: simultaneidade, repetição, fragmentação, colagem, diversidade, singularidade, descontinuidade, multiplicidade, comunicação simbólica e outros.

Os alunos que desenvolvem este trabaIho pertencem a uma classe social média e alta, habituados a consumir no seu dia-a-dia imagens veiculadas através da mídia (televisão, revistas, computador), sendo o computador o de maior interesse e domínio por parte deles. Optou-se em trabalhar a linguagem da mídia com o uso da informática, porque o aluno, nesta faixa etária, demonstra interesse pela comunicação simbólica utilizada pela mídia e desenvolve um pensamento hipotético dedutivo apreciando trabalhar com projetos (da elaboração do planejamento até a produção final). Os alunos demonstram consciência crítica sobre suas produções artísticas, que os levam, muitas vezes, à inibição e ao bloqueio de suas expressões visuais, já que consideram suas produções visuais inadequadas para a comunicação social, ou seja, limitam a comunicação visual somente ao "saber desenhar", desconsiderando outros recursos da linguagem visual.

As novas tecnologias também oferecem possibilidades de rever alguns conceitos sobre a produção artística. Para Pierre Lévy,

"[...] no novo regime de criação, o artista não executa mais a composição, a escrita ou o desenho de uma mensagem, mas concebe um sistema gerador de obras [...] A obra de arte deixa de ser uma cascata de interpretações para ser uma rede de operações interativas na trama do universo contemporâneo" (1998, p. 50; 54). 
Na produção do clip, ficou evidente como a informática não era mero recurso, mas implementava particularidades pertinentes à ela. $A$ técnica transforma-se em própria linguagem do meio. Trabalhar com o computador não restringe-se em usar imagens e dados disponíveis nele, e sim transformar um modo de fazer e de pensar a partir do uso de seus recursos. Ao modificar as imagens selecionadas no computador, os alunos apropriavam-se delas: as retiravam de um contexto e as colocavam em outros; descobriam soluções de animação de acordo com o ritmo das músicas; associavam som, imagem e tempo; modificavam as imagens no Paint ou Firework (programas de edição de imagem) excluindo e/ ou colocando novos elementos; atribuíam significados às imagens montadas.

A criação não se amparava na habilidade manual de fazer as imagens, mas na capacidade de conectar informações construindo um pensamento visual. A criação deixa de estar sustentada unicamente no saber fazer algo e passa a considerar os múltiplos "como" fazer, a incluir e ordenar realidades já existentes, como as imagens da web. Observou-se, com evidência, processos de criação e reflexão com o uso da web e das imagens do bando de imagens, contrariando posicionamentos que postulam a web como mera ferramenta desprovida de processos de aprendizagem na educação.

Ainda, pretende-se neste artigo compreender em que se diferencia uma proposta construída a partir de aprendizagem colaborativa, com o uso da web, em uma produção multimídia constituída de uma semiótica polifônica. Buscase perceber na produção dos videoclips a polissemia signíca nos próprios signos a partir das diferenças entre as mesmas músicas e entre signos em situações distintas. Aponta-se que a informática traz, potencialmente, relações diferenciadas na semiose dos signos pelas própri- as particularidades do meio. Os alunos ao acessarem imagens dadas na web tinham que selecioná-las e utilizá-las em outro contexto, já ativando outro modo de pensar. Mesmo que o tema seja bem familiar, a diversidade de linguagens (sonora, verbal e visual) faz com que os alunos tenham que deslocar suas representações imediatas e pensar em meios de resolver os desencaixes das linguagens, detendo-se no que está sendo dito, visto e ouvido. Inexiste uma representação idêntica para todas linguagens: as imagens mentais ao escutarem as músicas não eram idênticas as imagens selecionadas e construídas, que por sua vez, também diferenciavam-se das imagens sonoras. Ocorria um esforço constante de significação pelos alunos, buscando sair das imagens clichês.

Portanto, há o desafio de comunicar-se expressivamente com imagens pelo computador. Não basta só colocar as imagens nos slides, elas devem ter qualidades expressivas. Assim como a música tem particularidades, como o ritmo, as imagens também as têm. Por tratar-se de seqüência de imagens, teriam que ser animadas e não repetirem as mesmas soluções de composição e recurso visual. Tal desafio está presente, constantemente, nos clips: como podem tornar as imagens significativas e expressivas, ultrapassando os clichês?

A imagem digital surge como atualizações provisórias de um campo de possibilidades, deslocando a linearidade para uma rede de multiplicidades. A imagem tornando-se autorefente sem a conexão obrigatória com o objeto exterior. De acordo com Fonseca, "podemos supor que as potências de imagens digitalizadas instauram um novo regime semiótico em que o referente é anulado remetendo as imagens a si próprias" (2005, p. 127). A imagem não está mais no que é visível, todavia na montagem e na simulação. Esclarece-se, entretanto, que a ima- 
gem digital também precisa ser trabalhada para superar a condição do clichê. Segundo André Parente: "O desafio daquele que produz imagens é justamente saber em que sentido é possível extrair imagens (jamais vu, pura exterioridade) dos clichês (déjà vu, pura interioridade), imagens que nos dêem razão para acreditar nesse mundo em que vivemos" (1999, p. 42). Imagens que sendo digitalizadas se desprendem do objeto externo, tornando-se meta-imagens de um universo plástico que se atualiza conforme o contexto exigido.

\subsection{Concepção de Informação}

Observa-se, com certa freqüência, uma crítica quanto a inibição de criação pela informática em experiências na área de artes visuais. Entretanto tal inibição não ocorre pela imagem digital fornecida pelo computador, todavia antecede ao uso da informática, localizando-se, segundo Simondon (2003), na concepção de forma. Para substituir o problema da forma dada, do já existente, do clichê, Simondon utiliza o conceito de informação. Segundo ele, a informação não tem um sentido a priori, sendo aquilo que ainda não é hunamo, forma, indivíduo; é um virtual cheio de potencialidades. Informação como um signo a-significante que ganha significado somente ao passar pelo meio; no caso da produção dos videoclips, o computador como meio. Neste sentido, Simondon expõe que "a noção de forma deve ser substituída pela de informação" (2003, p. 115), uma vez que a informação pressupõe um equilíbrio metaestável, um equilíbrio que se dá justamente pela diferença entre os meios, obrigando individuações constantes, significações dadas pela experiência, já que inexiste um termo único, ao contrário da forma. De acordo com Simondon:

"[...] a informação é um início de individuação, uma exigência de individuação, nunca é uma coisa dada; não há unidade e identidade da informação, pois a informação não é um termo; ela supõe tensão de um sistema de ser; só pode ser inerente a uma problemática; a informação é aquilo por intermédio de que a incompatibilidade do sistema não resolvido devém dimensão organizadora na resolução; [...] poderíamos dizer que a informação é sempre no presente, atual, porque ela é o sentido segundo o qual um sistema se individua" (2003, p.110).

Podemos pensar a informação como um existente potencial em nível virtual que quando se atualiza, através de um determinado meio, se individua. Um existente que nos desacomoda exigindo uma resolução. Um signo a-significante anterior a significação. Nos videoclips muitas configurações reconhecidas adquirem significações diferenciadas em músicas diferentes ou a mesma música trabalhada por duplas diferentes. Por exemplo: a frase "o mundo vai acabar" foi visualizada por uma dupla como um bolo de recém-casados sendo destruído; por outra dupla como uma casa sendo destruída; e por outra, ainda, como uma situação de guerra. Ou, a mesma imagem em músicas diferentes, como cédulas de dinheiro: por uma dupla como o que traz felicidade; por outra como corrupção; por outra como tudo o que se quer no mundo. $\mathrm{Na}$ música, as imagens já trazem uma leitura, porém não são únicas; elas são alteradas conforme as combinações, no caso, alunos e informática.

Mesmo o que em um primeiro momento parece ser uma coisa simples: copiar/colar imagens da web, mostra-se como um dispositivo de reflexão, já que exige um (re)pensar sobre o conhecido e uma atribuição de sentido singular. Os alunos acessam a internet e o banco de imagens da escola selecionando imagens de acordo com o que desejam construir no clip. Ao se apropriar de imagens da internet atribuindo-lhe um significado próprio, a noção de informação parece mais evidente. Alguns alunos discutem sobre a $\mathrm{CPI}$ e outros assuntos encontrados na web. Fa- 
zem sátira e se divertem. Eles criam uma história a partir da realidade do cotidiano, uma maneira de compreender e significar a própria realidade. Por exemplo, eles aproveitaram um certo non sense sugerido pela música de Raul Seixas e recriam realidades ainda não pensadas.

A música tem informações que podem ser significadas de inúmeras maneiras. A informação desperta algo, não esgota como a forma. A partir da música, os alunos começaram a discorrer sobre vários assuntos não se preocupando em apenas ilustrar a música com imagens. Pode-se pensar a web como uma estrutura aberta com vários caminhos de entrada que abrem a outros caminhos. Parece muito simples navegar pela web, porém exige realizações de conexões que não são lineares. A fórmula: procuro e encontro, nem sempre funciona diretamente. A procura pode partir por várias entradas e o encontro dá-se por uma multiplicidade de saídas; somente fazendo conexões entre as informações é que chega-se a um lugar.

Visou-se neste trabalho investigar como produzir construções imagéticas nos encontros e desencontros das interpretações associativas, não se limitando a ilustrações e clichês, mas imergindo nos sentidos repletos de significações. Nas imagens digitais habitam uma usina de signos que devem ser navegados e (re)significados. Afirma-se, aqui, a importância de práticas pedagógicas que se fundamentam sobre metodologias multimídia que buscam visualizar configurações espaciais e temporais que subvertam estruturas lineares e dicotômicas através de formas de expressão construídas na multiplicidade (Oliveira, 2006).

\subsection{Concepção de Rede}

Deste modo, salientamos que para que possamos compreender as interfaces das tecnologias digitais para além de simples ferramen- tas, faz-se preciso sair de generalidades e de dicotomias como homem/máquina a fim de abarcar a noção de redes de interfaces. São conexões, reinterpretações, misturas, híbridos que sofrem constantes mutações pelos percursos da interface digital. Não basta identificar e denominar objetos fixos, contudo penetrar nas peculiaridades de como se dão suas constituições, como seus caminhos são formados, propostos e utilizados, resultando em novas passagens para outras conexões e relações.

Portanto, as interfaces digitais somente podem ser entendidas a partir do conceito de redes de interface, sendo o conceito de rede um de seus aspectos constitutivos. Outro conceito que nos ajuda a pensar sobre as redes é o conceito de rizoma criado por Deleuze e Guattari. Um rizoma, segundo ambos autores constituí-se de

\footnotetext{
"sistemas a-centrados, redes de autômatos finitos, nos quais a comunicação se faz de um vizinho a um vizinho qualquer, onde as hastes ou canais não preexistem, nos quais os indivíduos são todos intercambiáveis, se definem somente por um estado a tal momento, de tal maneira que as operações locais se coordenam e o resultado final global se sincroniza independente de uma instância central' (1995, p.27).
}

Redes nas quais qualquer ponto pode conectar com outro, sem um ponto fixo, sem ordem determinada, sem unidade fixa. São sistemas constituídos por um princípio de multiplicidade que busca unidade nos movimentos dos fluxos das redes que se configuram pelos agenciamentos entre sujeitos e tecnologia. Estes sistemas a-centrados não visam negar a existência do centro como configurador da unidade, mas auxiliam a pensar o centro incluso em um espaço composto por diversos centros ordenados de forma descontínua. Estes espaços sem estrutura central permitem construções 
desmontáveis e conectáveis que abre ao finito ilimitado e ao descentramento tanto do espaço quanto do sujeito. Multiplicidade móvel e heterogênea dos centros em rede aberta sem hierarquias, já que são compostos de modo autopoiéticos a partir de singularidades.

Ainda, pensando rede como rizoma podemos nos remeter à idéia do hipertexto nas construções multimídia. A estrutura hipertextual traz características peculiares ao contemporâneo, como a velocidade e as conexões. De acordo com Lévy: "Tudo se dá como se o autor de um hipertexto constituísse uma matriz de textos potenciais, o papel dos navegadores sendo o de realizar alguns desses textos colocando em jogo, cada qual a sua maneira, a combinatória entre os nós" (1999, p.57-61). De acordo com o autor (1993), o hipertexto apresenta seis princípios abstratos: princípio de metamorfose (permanente jogo com os atores envolvidos); principio de heterogeneidade (todos tipos de elementos e associações possíveis); princípio de multiplicidade (organização fractal); princípio de exterioridade (não possui uma unidade interna, dependendo de um exterior indeterminado); princípio de topologia (a rede é o espaço); princípio de mobilidade de centros (estrutura rizomática, não central). Um texto em formato digital, reconfigurável e multimídia, operando com os signos textuais, visuais e sonoros, em tempo real e em rede móvel, ligado por conexões e associações em nível molecular que produzem e transmutam o sentido.

O hipertexto como construção multimídia é um pensamento em rede e um instrumento de escrita-leitura coletiva. Para Parente: "Em torno do hipertexto encontramos alguns dos mais importantes paradigmas do pensamento da contemporaneidade - velocidade, nãolinearidade, interatividade, metamorfose, multiplicidade, entre outros. Com o hipertexto, descobrimos um pensamento da complexidade que se faz em rede" (1999, p.7). Mostra-se uma razão mais associada às redes de informação e comunicação do que às idéias platônicas. Devemos nos questionar como provocar e emergir estes aspectos rizomáticos de rede, produzindo outras relações signícas em processos de criação, e, conseqüentemente, instituições e subjetivações abertas à cooperação?

\subsection{Concepção de Criação}

Visando-se pensar sobre processos de criação na interface digital e, especificamente, com o uso da web, afirma-se, aqui, a pertinência de buscar modos de cognição gerados em processos que levem a criação. Coloca-se uma concepção de educação a partir de um arranjo que abrange cognição e criação. Tal visão inclusiva também é requerida por Bergson em sua obra $A$ evolução criadora uma vez que reivindica uma teoria do conhecimento que considere tanto a inteligência como a intuição. Para ele, os entraves do conhecimento não localizam-se em nenhum destas faculdades em particular, mas, ao contrário, na exclusão de qualquer uma delas, que, na maioria das vezes, conduzida pela ciência, dá-se sobre a criação que precisa ser resgatada. Ambas apresentam princípios distintos: a criação transita por um pensamento processual sobre a transformação constante das formas e a cognição por um pensamento que necessita da estabilidade para torná-las inteligíveis.

Se a inteligência se fixa nas determinações da matéria e nas finalidades da ação, a intuição, para Bergson, move-se pelos fluxos do movimento, pela constante transformação que dura, pela duração pertinente à ordem do tempo. A intuição nos assalta apresentando alguma coisa, sem que possamos remeter ao já feito anteriormente. Ela atualiza o virtual que constitui-se na experiência, já que não existe o dado a 
priori, mas o criado no vivido com a potência de se diferir. Ela nos surpreende, pois não é resultado da realização de uma finalidade; ela acontece. Todavia, não acontece sozinha, mas acompanhada pela inteligência. A intuição é o que torna possível a criação e vice-versa.

Observou-se que as crianças, ao produzirem o videoclip, também apoiavam-se no já conhecido, nos clichês. Os clichês estão presentes antes de se começar o trabalho, são as portas de entrada, os caminhos já trilhados, as falas prontas: é o que precisa ser superado para que ocorra a criação. Havia uma necessidade de serem acolhidos pelo familiar, de reduzir-se no clichê e calar o diferenciado. Os clichês já estão presentes nas imagens mentais de cada aluno quando escutam a música, quando navegam pela internet, quando utilizam o banco de imagens, ou mesmo, quando desenham imagens sobre folhas brancas. Uma folha em branco, uma tela vazia do computador não é um espaço pleno de possibilidades, mas, ao contrário, é um espaço cheio de marcas direcionadas, de limites a serem rompidos. Deleuze coloca que: "En efecto, seria un error creer que el pintor trabaja sobre una superficie blanca y virgen. La superficie está ya por entero investida virtualmente mediante toda classe de clichés com los que tendrá que romper" (2002, p. 21). Não constróise um conhecimento totalmente novo, precisamos de pontes, de tripés para ir se apoiando. No clip, a transgressão dos clichês, das imagens prontas, era um dos critérios avaliativos que orientavam os alunos. Eles deparavam-se com os clichês e ora aceitavam ora transgrediam. Ir além dos clichês, chegar aum resultado desconhecido, inventar realidades são ações do pensamento.

A superação dos clichês ocorria em processo de colaboração, em que o sujeito não é a fonte da invenção, uma vez que a invenção é fruto do próprio produto e das contingências do mundo. Ele participa da invenção ao ser inventado durante o processo. Incide em um processo coletivo no qual o sujeito é apenas partícipe, protagonista coletivo e processual. Interagir implica em um silenciar, um suspender, um não saber diante à multiplicidade do viver. A multiplicidade se apresenta como estratégia de criação e saída de um processo de massificação, e até de idiotização educacional. A proposta de fazer um videoclip em dupla é intencional para que os alunos tenham que falar sobre suas idéias e sensações percebendo que existem inúmeras maneiras de olhar, que as coisas podem ser de outro modo. Não são afirmativas de um ser que transmite um saber; não é pretensão de uma verdade, mas invenções de realidades. São estratégias para que o sujeito se diferencie de si na polifonia das falas e invente, constantemente, uma narrativa de si. Algo que atice a vontade pela diferença e o mal estar pela mesmice.

A experiência estética vem da medida em que eu me abro para aquilo que me olha. Os alunos escutam as músicas, olham as imagens, constroém composições, bem como as próprias imagens, sons, composições servem de espeIhos por onde eles têm contato com suas virtualidades, com o que lhes estava intocado, embora presente. A criação é uma maneira de nos deixarmos presenciar. A imagem não é algo que eu vou conhecer, mas algo que vai fazer-me (des) conhecer, isto é, que faz eu conhecer algo que não sabia.

Colocamos, aqui, que o ensino com as NTIC (Novas Tecnologias de Informação e Comunicação) não é por informação, mas por problematizações e invenção de realidades via processos interativos coletivos com base na cooperação. Os conceitos não são simples e universais, mas abertos, complexos, múltiplos em um ambiente plástico, híbrido cognitivo em que cada interpretar abre outro interpretar, abrindo 
um ciclo de recursividade criadora.

\subsection{Rede de Operações Interativas}

Busca-se apontar como os modos de operações interativas, com o uso das NTIC, podem alterar os modos de conhecer e gerar processos cognitivos criativos. Como Bergson nos fala: "[...] o que fazemos depende daquilo que somos; mas é necessário acrescentar que somos, em certa medida, aquilo que fazemos, e que nos criamos continuamente a nós próprios" (1964, p. 46). Observamos que as NTICs (Novas Tecnologias de Informação e Comunicação), mais propriamente as produções audiovisuais, apresentam-se como um campo de produção de sentidos que podem nos oferecer outros modos de olhar, perceber, agir, e pensar; mudanças qualitativas na ecologia dos signos.

Assim destacamos os modos de operações interativas na produção de conhecimento. Ressaltamos que apenas o uso destas tecnologias não implica necessariamente em interatividade. A tecnologia digital é uma interface que pode promover interatividade caso haja intencionalidade para este modo de inter-relação social. Deve-se provocar situações de desequilíbrio, orientando para construção do conhecimento e não somente no acesso a informação. O conhecimento se produz na interatividade, conforme Piaget. Para conhecer é preciso atuar sobre o objeto e interagir com outros sujeitos. A aprendizagem ocorre em um processo de modificação estrutural produzida em um jogo de assimilação e acomodação.

Como as interfaces da informática são potencialmente interativas, já que o conhecimento gera-se pela intervenção do interator e têm inúmeros caminhos para ocorrer, gerando um modo particular de cognição. Sabemos que tal potencial nem sempre é explorado, sendo que em muitas vezes, fica-se preso aos ranços do pensamento linear, direcionado a um estímulo/resposta, a um caminho reduzido ao acerto/ erro. A possibilidade de construção do conhecimento via criação de realidades por múltiplos caminhos fica anulada.

Observou-se que dentro de processos interativos, o lugar do professor também foi alterado no laboratório de informática. Os alunos ficavam de frente para o computador e todos de costas para o professor. O professor tinha voz de ordem em raros momentos: informações gerais sobre o software, recados, cuidado com o excesso de barulho. A intervenção por parte do professor era solicitada pelas duplas quando tinham dúvidas, para mostrar descobertas ou pedir pareceres, ficando o professor com um papel de mediador do conhecimento. O professor desconhecia informações que os alunos e a responsável técnica do laboratório tinham. Os alunos desconheciam, as do professor e as da responsável técnica. E ela desconhecia, as dos alunos e do professor. Portanto, ninguém detinha o saber; todos precisavam se ajudar para construir o trabalho. Em alguns momentos, se presenciou uma estrutura do saber sem hierarquização conduzida pela própria experiência.Todos, quando imersos no processo de criação, eram conduzidos pela experiência estética que indicava trajetos imprevistos. Na criação, a ética da sala de aula é conduzida pela estética da experiência.

Não são afirmativas de um ser que transmite um saber; não é pretensão de uma verdade, mas invenções de realidades. São estratégias para que o sujeito se diferencie de si na polifonia das falas e invente, constantemente, uma narrativa de si. Algo que atice a vontade pela diferença e o mal estar pela mesmice.

\section{Desenvolvimento do Trabalho}

Este trabalho parte de uma abordagem curricular sobre as imagens veiculadas na mídia, 
enfatizando-se a associação entre as mensagens visuais, sonoras e verbais. O uso das NTIC (Novas Tecnologias de Informação e Comunicação) também faz parte da programação curricular, uma vez que acreditasse que tais tecnologias promovem modos específicos de aprendizagem.

Como quesito para o trabalho, os alunos realizaram uma pesquisa teórica sobre os movimentos artísticos de vanguarda do início do século XX: expressionismo, fauvismo, cubismo, abstracionismo, dadaísmo, surrealismo, op-art e pop-art. Estes movimentos são estudados como a gênese das imagens contemporâneas, uma vez que se libertam da exigência da representação exterior e exploram a imagem como signos que possibilitam jogos simbólicos com novos significados, através da: deformação, da apropriação dos signos, do estudo de composição, de recorte/colagem, das associações surreais, da desconstrução das imagens do cotidiano. Em particular, enfatiza-se os artistas Escher e Duchamp na compreensão da coexistência de realidades múltiplas e da (re)invenção do cotidiano.

Após, apresentados os trabalhos e analisadas as imagens, introduz-se a proposta do videoclip. A produção dos videoclips se dá a partir: da escolha da música que a dupla de alunos deseja trabalhar; da discussão e reflexão sobre o significado da música para dupla e da interpretação sonora e escrita para transposição visual na construção de um roteiro que orienta toda a etapa desenvolvida no laboratório de informática. Após, realiza-se uma construção multimídia no laboratório de informática, assentada na pluralidade de linguagens através da compreensão da estrutura da imagem até uma sintaxe na organização de imagens, textos e sons. Ao trabalhar construções multimídias, desenvolvem-se capacidades associativas entre as lin- guagens e estruturas indefinidamente recursivas dos sentidos.

\subsection{Produção do Videoclip}

A proposta de produção do videoclip, no laboratório de informática, começa com a digitalização das músicas e das imagens desejadas pela dupla em horário extra-classe. No primeiro encontro utilizam-se trabalhos de anos anteriores para exemplificação e visualização das possibilidades dos programas; também apresenta-se os programas disponíveis para os trabalhos: Paint, Fire Work, Photo Story e Power Point. Os alunos podem escolher qual programa desejam utilizar no seu trabalho, dependendo dos efeitos e soluções que cada programa possibilita. Também podem sugerir e usar outros programas não indicados.

A produção do videoclip ocorre com base: roteiro prévio realizado em aula, imagens e músicas digitalizadas extra-calsse, banco de imagens do colégio (estáticas e animadas), acesso livre a web, efeitos para texto/imagens, possibilidades de fundos e texturas, movimento (transição/animação), sincronismo entre som e imagens, observação da composição visual. O acesso à web é livre, esclarecendo que o objetivo foca-se na produção do trabalho, não sendo permitido o uso para outros fins (jogos, chats, sites impróprios para à faixa etária); o que é respeitado ao longo do trabalho, pois os alunos ficam absorvidos em sua realização.

A execução deste trabalho também é possível pela infra-estrutura dos laboratórios de informática. O Colégio conta com quatro laboratórios de informática, sendo o que atende os alunos da $6^{\underline{a}}$ série-tarde (em torno de 120 alunos - 40 alunos por turma), têm 22 máquinas conectadas à internet, numa velocidade de 865.70 kilobits/segundo. Em cada laboratório, 
os professores das disciplinas curriculares contam com o auxilio de um técnico responsável que auxilia tanto no planejamento das propostas, indicando programas adequados e possibilidades, quanto na realização das aulas. Propiciase um dialogo interessante entre os saberes técnicos (da responsável), os saberes pedagógicos (dos professores) e os saberes dos alunos.

Na etapa da edição das imagens, trabaIhou-se com o software Paint e Firework, da Macromédia, por ser um programa de desenhos baseado em vetores que possibilita a combinação de filtros e textos de maneira ágil, e tamanho reduzido, o que conta muito na montagem e agilidade áudio visual. Por ser um software des-

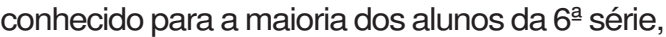
na primeira aula foram apresentadas as ferramentas para criar e modificar imagens. Após a edição das imagens, trabalhou-se com o software Power Point e Photo Story 3 (livre), da Microsoft, por incluir recursos que permitem que se crie um slideshow com as imagens digitalizadas, oferecendo recursos de edição de uma história. O produto final dessa criação são videoclips que variam de 3 minuto até no máximo 5 minutos, de tamanho médio de 2.500KB.

Ao longo do trabalho, observou-se que os alunos utilizaram o laboratório de informática, que é comum a todas disciplinas, de maneira diferenciada nas aulas de artes. A responsável técnica de informática comentou que, no trabaIho do clip, os alunos desenvolviam atitudes mais autônomas e criativas, começando pela maneira com que se relacionavam com o computador. Em outras disciplinas, é fornecido um endereço a ser percorrido pelo aluno. Por exemplo, em trabalhos de outras disciplinas dá-se o caminho a ser percorrido: unidade $\mathrm{u} / \mathrm{ciên}$ cias/meio ambiente/animais. Os alunos realizam o trabalho pesquisando somente dentro do endereço fornecido. No trabalho do clip, os alunos pesquisam em todas as unidades do computador (banco de imagens, sons, endereços de outras disciplinas) e na internet. Eles, segundo uma observação da responsável técnica, descobrem o que contém o computador, tanto em informações como os recursos dos softwares. E ainda alimentam o computador com mais dados e novos programas.

A observação do espaço diferenciado era frisada em várias aulas, quando se colocava que tais atitudes, como: navegar pela internet, escutar música, trazer fones de ouvido, baixar programas, auxiliar os colegas de outras duplas..., se restringiam às aulas de artes. A autonomia dos alunos ia desde trazer aparelhos, programas (como o gimpt para resolução de imagens), indicar sites (como o site sempreteen.com.br para fazer gifs), fotografar, filmar em vídeo; até à construção do próprio clip: seleção das imagens, montagens, uso de programas de imagem, aplicação de recursos visuais, utilização simultânea de vários softwares e linguagens. Os alunos chegavam na aula, abriam seus trabalhos e davam continuidade, sem esperar qualquer indicação da professora ou da técnica. Solicitavam auxilio de modo particular quando precisavam.

Outro elemento importante observado no trabalho com o uso da web é a própria escolha das imagens. Os alunos não se satisfazem com as primeiras imagens encontradas e dedicamse a achar aquelas imagens que correspondem com seus desejos. A pesquisa realizada previamente, em sala de aula, sobre os movimentos de arte do século $X X$, propiciou um contato com diversos modos de expressão e ampliou a apreciação sobre as imagens. Além disso, a seleção feita na banco de imagens da escola (cerca de cinco mil imagens) e na internet propiciou ultrapassar um campo conhecido, navegar sobre o que nem se espera encontrar. Como muitos alunos expuseram "tem muito lixo na internet, nem tudo serve". 
Há um aprendizado em selecionar o que pode ser significativo. Algumas alunas quando terminaram de juntar as imagens que estavam soltas na internet, descobriram que elas formavam uma única sobre pessoas desaparecidas; o que assustou foi ver que as imagens da internet não são neutras, aleatórias. Esta dupla escolheu algumas imagens extremamente violentas e questionei se era preciso ir até este extremo para expressar a violência; sugeri que trocassem de imagens. Elas argumentaram que visavam um contraste e que naquela parte da música seria a culminância. Não era só colocar as imagens, elas tinham um propósito. Permaneceram as imagens no clip, uma vez que era o modo delas de distender ao máximo a violência: a violência pode ser pior do que pensamos.

O fazer do clip visa ser estimulador de novas proposições e não inibidor no já conhecido. A música e as imagens devem lançar as crianças na busca de construir um território peculiar, mesmo se apropriando de muitos clichês. Como no clip de certa dupla, por exemplo, elas utilizam as personagens Jack e Salle como protagonistas da música e deram todo o clima de terror à música romântica. As alunas escolheram trabalhar com um tema romântico associando personagens de terror. Há uma distância do tema inicial, uma reinvenção da música, uma autoria de sua própria história. Esta dupla se manteve muito envolvida ao longo de todo o trabalho: elas criaram o seu próprio romance.

Constatou-se que o ato constante de navegar pelas informações ampliou o imaginário dos alunos. Eles traziam um conhecimento prévio adquirido que era desconstruído pela navegação das imagens na web, pelas imagens do banco de imagens, pelas imagens estudas na história da arte, pelas imagens sugeridas pelos colegas e pela professora, pelas imagens modificadas pelos programas. As imagens, depois de selecionadas, eram trabalhas nos programas de edição de imagem, construindo uma outra imagem pela dupla. Ocorria uma aprendizagem coletiva em que o conhecimento construído ultrapassava o campo já conhecido. A aprendizagem colaborativa explicitou-se tanto nas atitudes inter pessoais quanto no próprio conhecimento coletivo construído.

A construção de conhecimento é vista como coletiva, já que não é determinado pelas necessidades particulares do indivíduo ou por uma intenção determinada pelos elementos envolvidos que definem a prioria obra a ser executada. Uma produção coletiva se constitui como um efeito de contingências de um processo criativo e emerge como uma obra original e singular, já que é criada a partir dos jogos pertinentes aos agenciamentos entre os sujeitos/ máquina e obra, compostos por elementos singulares em um recorte de espaço/tempo histórico. Uma autoria coletiva como processo aberto e complexo em que cada um é autor de suas singularidades.

Também, observou-se que relações de competitividade deram acesso às relações de cooperação. Inicialmente, os alunos ficavam fechados em seus trabalhos, não querendo compartilhar o que havia descoberto. Com o passar das aulas, perceberam que as imagens eram de domínio público e o que as tornavam singulares era o modo como eles intervinham nas imagens, faziam as composições, de acordo com as necessidades do trabalho. A partir deste momento, os alunos se ajudavam mutuamente para encontrar sites, figuras, efeitos, recursos dos programas. Era uma situação comum, alunos em outras duplas apreciando ou ajudando os colegas. Na fase de conclusão, quem ia terminando o seu trabalho ficava de monitor para ajudar outras duplas. Na maioria das duplas era evidenciado o companheirismo: as duplas ti- 
nham que se entender para o trabalho ficar pronto; resultou em relações de amizade e prazer em ver como coletivamente o trabalho ficava surpreendente e interessante.

\subsection{Produto Final}

Os trabalhos concluídos foram exibidos em sala de aula com o uso do Data show, sendo apresentados por cada dupla de alunos para o grande grupo. Também foram exibidos na Mostra de Informática do Colégio, ficando cada dupla responsável por um horário para mostrar pra comunidade escolar (alunos, professores, funcionários e pais) o produto final e explicar o processo de construção. A exibição dos trabalhos para a comunidade escolar propicia que os alunos tenham uma experiência concluída, do planejamento até o produto final veiculado na comunidade, atribuindo um sentido de autoria ao seu fazer.

\section{Considerações Finais}

Ao realizar este trabalho, foi possível perceber a aquisição de algumas capacidades pelos alunos, tais como: autodireção, criação, formulação e resolução de problemas, integração, comunicação interpessoal e espírito de cooperação, compreensão dos códigos da linguagem da arte para concretizar, expressar, comunicar, ler e conhecer os objetos da produção artística. Percebe-se que os procedimentos escolhidos durante o projeto ampliaram o poder de percepção sensível, de memória significativa e de imaginação criadora levando a aprendizagem artística e estética. Também foi interessante de analisar como as mesmas músicas tinham interpretações diferentes, sobre os seus valores, entre os grupos e como diferia a produção dos meninos e das meninas.

Observou-se, também, que o ambiente da informática facilitou a autodireção e o espíri- to de cooperação, pois os alunos chegavam no laboratório de informática e interagiam com o computador com facilidade, surpreendendo os professores, e prestando auxilio para quem necessitasse. Demonstravam prazer em ajudar os outros fornecendo conhecimentos técnicos e de informação (onde se encontrava tal imagem, como conseguiu tal efeito etc). Sobre a formação, Philippe Perrenoud assinala: "Formar para as novas tecnologias é formar o julgamento, o senso crítico, o pensamento hipotético e dedutivo, as faculdades de observação e de pesquisa, a imaginação, a capacidade de memorizar e classificar, a leitura e a análise de textos e de imagens, a representação de redes, de procedimentos e de estratégias de comunicação" (2000). Expande -se o aproveitamento das novas tecnologias, uma vez que implica em mudanças de atitudinais, como a colaboração.

O ensino no virtual não é por quantidade de dados, mas problematizações de realidades via processos interativos coletivos com base na cooperação; os conceitos são abertos, complexos, múltiplos, subjetivos com contorno irregular em um encontro dialógico. Um ambiente plástico, híbrido cognitivo em que cada interpretar abre outro interpretar, abrindo um ciclo de recursividade criadora em que expressar implica em uma natura intensiva mais do que extensiva. O navegar pelas informações promove uma autoria coletiva feita pela interlocução, interação e polifonia da linguagem e polissemia do sentido. No clip, a transgressão dos clichês, das imagens prontas, era um dos critérios avaliativos que orientavam os alunos. Ir além dos clichês, chegar a um resultado desconhecido, inventar realidades são ações do pensamento.

A construção coletiva do conhecimento também explicitou outro modo de aprendizagem. A aprendizagem colaborativa tem a horizontalidade como base, viabilizando exercícios 
de cidadania na medida em que a produção do sujeito possa interferir na configuração coletiva do conhecimento. Há uma valorização das interferências individuais, já que elas tornam-se imprescindíveis em uma construção coletiva singulares. Neste contexto, o professor apresenta-se como um facilitador e mediador, atuando no intermezzo das relações transsubjetivas.

A educação para a participação, para a valorização e comprometimento com a instância coletiva vem a corporificar o conhecimento como rede. Este ambiente coletivo é uma usina de signos que partem de um objeto a ser estudado e o transcende na medida em que não existe uma finalidade determinista. A informática apresenta peculiaridades que são novas portas para a saída da massificação, como comenta Guattari:

\begin{abstract}
"O melhor é a criação, a invenção de novos Universos de referência; o pior é a mass-midialização embrutecedora, à qual são condenados hoje em dia milhares de indivíduos. As evoluções tecnológicas, conjugadas a experimentações sociais desses novos domínios, são talvez capazes de nos fazer sair do período opressivo atual e de nos fazer entrar em uma era pós-midia, caracterizada por uma reapropriação e uma re-singularização da utilização mídia. (Acesso a bancos de dados, às videotecas, interatividade entre os protagonistas etc...)" (1992, p.16).
\end{abstract}

O que tal experiência produz é uma modificação nos modos de fazer, uma vez que não se limita à disciplina de Artes. Há a construção de um conhecimento que não é "saber fazer um videoclip", uma tarefa cumprida. Os alunos chegam a um resultado, um produto final, entretanto o conhecimento produzido encontra-se na processualidade, nas maneiras em que se experimentam realizando o trabalho, nas posturas de enfrentar os desafios, nas conecções do pensamento construindo realidades, e até nos desejos produzidos.

E inegável que as NTICs vem alterando os modos de relacionamento social, promovendo mudanças que ultrapassam o simples uso da tecnologia, entretanto temos que nos questionar em que nível esta mudanças atingem os processos de cognição na contemporaneidade e que mutações esta nova interface digital provoca. O mundo digital propõe novas formas de se lidar com a informação e a comunicação, outros modos de habitar o espaço-tempo, outras concepções sobre a realidade (virtual e atual), novas construções imagéticas constituindo-se, portanto, portador de mutações culturais da humanidade.

Devemos considerar de que maneira as NTICs nos lançam a potencialidades como diferencial uma perspectiva humanista ou nos reduzem à sistemas fechados de conservação ou até mesmo de exclusão. As tecnologias não são boas nem más, e nem neutras, não podendo ser vistas isoladas, mas em seus modos de agir, de subjetivar, de produzir sentido e conhecimento, de provocar mudanças qualitativas na ecologia dos signos, de promover outras relações intersubjetivas.

\section{Referências}

DELEUZE, G. Gilbert Simondon, o indivíduo e sua gênese físico-biológica. In: Cadernos de Subjetividade - O Reencantamento do Concreto. São Paulo, Hucitec, 2003.

DELEUZE, G. e GUATTARI, F. Mil platôs - capitalismo e esquizofrenia. São Paulo: Ed.34, 1995, vol. 1. 
FONSECA, T. Poéticas do Virtual e os Processos de subjetivação. In: Informática na Educação: Teoria \& Prática-Revista do PGIE da UFRGS. V.08-1, 2005.

GUATTARI, F. Caosmose. Rio de Janeiro, Ed. 34, 1992.

LÉVY, P. A inteligência coletiva. São Paulo, Edições Loyola, 2000.

, P. Cibercultura. São Paulo, Ed. 34, 1999.

P. A máquina universo. Porto Alegre, Artes Médicas, 1998.

P. As tecnologias da inteligência. Rio de Janeiro, Ed. 34, 1993.

PARENTE, A. O virtual e o hipertextual. Rio de Janeiro, Pazulin, 1999.

OLIVEIRA, A. e FONSECA, T. Conversas entre Escher e Deleuze: tecendo percursos para se pensar a subjetivação. In: Revista Psicologia e Sociedade. Vol.18, nº 3, set/dez, 2006.

PERRENOUD, P. Dez Novas Competências para Ensinar. POA, Artes Médicas, 2000.

SIMONDON, G. A Gênese do Indivíduo. In: Cadernos de Subjetividade - O Reencantamento do Concreto. São Paulo, Hucitec/EDUC, 2003.

\section{Andréia Machado Oliveira}

Mestre em Psicologia Social e Institucional-UFRGS, doutoranda do Programa de Pós-Graduação em Informática na Educação-PPGIE.

\section{Tania Mara Galli Fonseca}

Psicóloga, docente nos programas de pós-graduação em Informática na Educação - UFRGS e em Psicologia Social e Institucional - UFRGS.

\section{Maria Cristina Villanova Biazus}

Artista plástica, docente do Instituto de Artes e do programa em Informática na Educação - UFRGS. 
